\title{
The Long-Term Safety of S-Flurbiprofen Plaster for Osteoarthritis Patients: An Open-Label, 52-Week Study
}

\author{
Ikuko Yataba $^{1} \cdot$ Noboru Otsuka $^{1} \cdot$ Isao Matsushita $^{1} \cdot$ Hideo Matsumoto $^{2} \cdot$ \\ Yuichi Hoshino ${ }^{3}$
}

Published online: 26 May 2016

(c) The Author(s) 2016. This article is published with open access at Springerlink.com

\begin{abstract}
Background and objectives The newly developed S-flurbiprofen plaster (SFPP) is a tape-type patch that shows innovative percutaneous absorption. This study was designed to evaluate the safety of a long-term 52-week SFPP application to osteoarthritis (OA) patients.

Methods This was a multi-center, open-label, uncontrolled prospective study that included 201 OA patients. SFPP at $40 \mathrm{mg} /$ day was applied to the site of pain in 101 patients and at $80 \mathrm{mg} /$ day ( 2 patches) in 100 patients at a total of 301 sites for 52 weeks. The affected sites assessed included the knee (192), lumbar spine (66), cervical spine (26), and others (17). Drug safety was evaluated by medical examination, laboratory tests, and examination of vital signs. Efficacy was evaluated by the patient's and clinician's global assessments and clinical symptoms.

Results Most patients (80.1\%) completed the 52-week SFPP application. The majority of drug-related adverse events (AEs) included mild dermatitis at the application sites and occurred in $46.8 \%$ of the sites. No photosensitive dermatitis was observed. Systemic AEs occurred in $9.0 \%$ of the patients; a serious AE (gastric ulcer hemorrhage) occurred in one patient. No clinically significant changes in the laboratory tests and vital signs were observed. The efficacy evaluation showed an improvement from 2 weeks
\end{abstract}

Noboru Otsuka

n-otsuka@so.taisho.co.jp

1 Development Headquarters, Taisho Pharmaceutical Co., Ltd., 3-24-1 Takada, Toshima-ku, Tokyo 170-8633, Japan

2 Institute for Integrated Sports Medicine, School of Medicine, Keio University, Tokyo, Japan

3 Orthopedic Surgery, School of Medicine, Jichi Medical University, Tochigi, Japan after the SFPP application, which continued during the 52 weeks' treatment.

Conclusions No apparent safety concerns were observed, even during the long-term SFPP application. Therefore, SFPP could be an additional pharmacotherapy in OA treatment.

\section{Key Points}

The S-flurbiprofen plaster (SFPP) with an innovative percutaneous absorption was developed for the treatment of osteoarthritis (OA) commonly seen in the elderly.

Long-term 52-week application of SFPP was well tolerated in the OA patients, who had a mean age of 66.3 years.

\section{Introduction}

Osteoarthritis (OA) is strongly linked to aging, and characterized by chronic pain, inflammation, and impaired overall functioning, significantly affecting quality of life $[1,2]$. Non-steroidal anti-inflammatory drugs (NSAIDs) are widely used in the pharmacotherapy of OA [3]. Although oral NSAIDs in particular have been used as firstline therapy for many years, concerns about adverse reactions related to class effects of NSAIDs such as gastrointestinal injuries and related hemorrhage are increasingly seen in the elderly patient [4-6] 
In recent years, the efficacy of topical NSAIDs is increasingly recognized and, currently, several clinical practice guidelines highly recommend topical NSAIDs over oral formulations [7-12].

S-flurbiprofen plaster (SFPP) is a tape-type patch that contains S-flurbiprofen (SFP)the active ingredient of flurbiprofen (FP), which has a potent cyclooxygenase (COX)inhibitory effect-and has been developed to achieve improved percutaneous absorption of SFP and its penetration into deep tissues. A clinical pharmacology study of SFPP in knee OA patients showed high penetration of SFP into the synovial tissue [13]. In addition, 2-week randomized controlled studies demonstrated the superior clinical efficacy of SFPP over that of the placebo [14]) and an FP patch [15], which suggested that SFPP might be useful for the short-term treatment of OA.

Systemic exposure to SFP following the application of $80 \mathrm{mg} /$ day of SFPP (two patches/day) for 7 days was estimated to be comparable to that of oral formulations of FP [14]. Adverse reactions considered as a class effect of NSAIDs include gastrointestinal, renal, and cardiac disorders [16]. These adverse reactions rarely occurred in the 2-week SFPP studies [14, 15]. However, in clinical practice, topical NSAIDs are commonly used as long-term treatments, including their intermittent use in several OA treatment paradigms. Thus, here, we evaluated the safety of SFPP applied to OA patients at doses up to $80 \mathrm{mg} /$ day for 52 weeks.

\section{Method}

\subsection{Study Design and Participant Selection}

This was a phase III, multi-center, open-label, uncontrolled prospective study conducted between May 2012 and December 2013 at 11 study sites in Japan. The Declaration of Helsinki and Good Clinical Practice guidelines were followed throughout the study. The protocol and informed consent form were approved by the institutional review board at each participating study site. (Trial registration: JapicCTI-121840.)

Osteoarthritis patients with moderate or severe pain in a major joint, and who were $\geq 20$ years of age and had provided written informed consent were included. The diagnosis of OA was based on both radiographic evidence and clinical symptoms determined by the clinician.

Patients who had three or more symptomatic OA sites were excluded. Patients were also excluded if they had diseases or required treatments that might affect the safety or efficacy assessment of NSAIDs, i.e., complication of gastrointestinal ulcers or other joint diseases such as rheumatoid arthritis. In principle, the concomitant use of oral NSAIDs and other analgesics as well as that of antiulcer and gastrointestinal agents was prohibited.

SFPP is a tape-type patch, $10 \mathrm{~cm} \times 14 \mathrm{~cm}$, containing $40 \mathrm{mg}$ of SFP per patch (Tokuhon Corporation, Tokyo Japan). The condition of the OA sites from the whole body were assessed by a clinician, and one or two painful sites were selected for the study. SFPP was applied at a daily dose of one patch per site to be assessed for 52 weeks. The site to be assessed was not changed during the study.

\subsection{Study Assessments}

Drug safety was assessed by medical examination by the clinician; blood and urine tests (blood cell count, hepatic function, and renal function); and blood pressure and pulse rate at Day1 (before the application; baseline), 2 and 4 weeks after the application, and every 4 weeks thereafter until 52 weeks.

The relationship between SFPP and an adverse event (AE) was assessed using a 4-point scale ("related," "probably related," "possibly related," and "not related") by the clinician. All the "related," "probably related," and "possibly related" scores were defined as "Drug-related AE." In addition, the severity of each AE was determined on a 3-point scale (mild = treatment not required or daily living not affected, moderate $=$ some treatment required or daily living affected, and severe = particular emergency treatment required or daily living complicated). Since SFPP is a topical formulation, AEs were assessed separately for local AEs at the application sites (skin symptoms) and systemic AEs, except those at the application sites.

The efficacy of SFPP in the outpatients was assessed by the patient's and clinician's global assessments as well as clinical symptoms (CS) at 2 weeks before the application (screening), Day1 (before the application; baseline), 2 and 4 weeks after the application, and every 4 weeks thereafter until 52 weeks. The patient's and clinician's global assessments consisted of a 5-point scale (marked, moderate, mild, not changed, and worse). The severity of CS was assessed for seven parameters (exercise pain, rest pain, local tenderness, swelling, local heat sensation, limitation of range of motion, and disability of activities of daily living [ADL]) on a 4-point scale ( 0 = none, $1=$ mild, $2=$ moderate, and $3=$ severe $)$, which allowed for the calculation of the total clinical symptoms (tCS) score.

\subsection{Statistical Analysis}

The planned sample size was set to 100 patients in each treatment group to mainly evaluate drug safety during the long-term application of SFPP. 
All analyses were carried out according to the prespecified statistical analysis plan using $\mathrm{SAS}^{\circledR}$ 9.2. The significance level was set at $5 \%$ (two-sided). Missing data at the end of the study period were imputed using the last observation carried forward (LOCF) method; missing data at other time-points were not imputed.

The safety analyses were based on the safety population that comprised all the patients who had applied SFPP at least once and of whom safety data had been obtained after the SFPP application. The number and percentage of patients who had an $\mathrm{AE}$ were summarized using the Medical Dictionary for Regulatory Activities (MedDRA/J ver.16.1) terminologies (system organ class and preferred term). Continuous outcomes in the laboratory tests and vital signs were analyzed using a paired $t$ test.

Efficacy analyses were based on the full analysis set (FAS) that comprised all the patients who had applied SFPP at least once and for whom the efficacy data had been obtained after the SFPP application. For the efficacy outcomes, the descriptive statistics were summarized by the treatment group and each time-point, and the tCS was analyzed using a paired $t$ test.

\section{Results}

\subsection{Patient Disposition}

The patient demographic characteristics are listed in Table 1. The study included 201 OA patients. The study population comprised 50 males and 151 females aged $66.3 \pm 11.8$ years (mean \pm standard deviation) and a body mass index (BMI) of $24.76 \pm 3.86 \mathrm{~kg} / \mathrm{m}^{2}$. The sites assessed are given in Table 2. A total of 301 sites were assessed for the 201 patients since two sites had to be assessed for the 100 patients in SFPP $80-\mathrm{mg}$ group. The site with the most assessments was the knee $(n=192,63.8 \%)$ followed by the lumbar spine $(n=66,21.9 \%)$. The combination of both knees was the most common site combination in the SFPP $80-\mathrm{mg}$ group $(n=66,66.0 \%)$.
Table 2 Sites assessed

\begin{tabular}{|c|c|c|c|}
\hline Site & $\begin{array}{l}\text { Total } \\
n=301\end{array}$ & $\begin{array}{l}\text { SFPP } 40 \mathrm{mg} \\
n=101\end{array}$ & $\begin{array}{l}\text { SFPP } 80 \mathrm{mg} \\
n=200\end{array}$ \\
\hline \multicolumn{4}{|c|}{ Single sites, $n(\%)$} \\
\hline Knee & $192(63.8)$ & $46(45.5)$ & $146(73.0)$ \\
\hline Lumbar spine & $66(21.9)$ & $39(38.6)$ & $27(13.5)$ \\
\hline Cervical spine & $26(8.6)$ & $11(10.9)$ & $15(7.5)$ \\
\hline Shoulder & $9(3.0)$ & $3(3.0)$ & $6(3.0)$ \\
\hline Elbow & $3(1.0)$ & $1(1.0)$ & $2(1.0)$ \\
\hline Hip & $2(0.7)$ & & $2(1.0)$ \\
\hline Hallux & $1(0.3)$ & $1(1.0)$ & \\
\hline Thoracic spine & $1(0.3)$ & & $1(0.5)$ \\
\hline \multirow[t]{2}{*}{ Ankle } & $1(0.3)$ & & $1(0.5)$ \\
\hline & & & $\begin{array}{l}\text { SFPP } 80 \mathrm{mg} \\
n=100\end{array}$ \\
\hline \multicolumn{4}{|c|}{ Combination sites, $n(\%)$} \\
\hline \multicolumn{2}{|l|}{ Both knees } & & $66(66.0)$ \\
\hline \multicolumn{2}{|c|}{ Lumbar and cervical spine } & & $12(12.0)$ \\
\hline \multicolumn{2}{|c|}{ Knee and lumbar spine } & & $11(11.0)$ \\
\hline Others & & & $11(11.0)$ \\
\hline
\end{tabular}

A total of 201 patients received the study drug (SFPP), of whom 161 completed the study (Fig. 1). Fourteen patients discontinued from the study as the result of an AE. The application periods of SFPP and the patient disposition per treatment group for each period are listed in Table 3 . Of the 201 patients, 161 applied SFPP for 52 weeks or longer. Of these, $92.5 \%$ (186/201 patients) had more than $80 \%$ application rate (the actual total number of patches during the application period/the prescribed number of patches during the application period).

\subsection{Safety Evaluations}

Skin symptoms that occurred at least once during each application period were observed at 141 of the 301 application sites (Table 4). These included application site
Table 1 Patient demographic characteristics

\begin{tabular}{llll}
\hline & $\begin{array}{l}\text { Total } \\
n=201\end{array}$ & $\begin{array}{l}\text { SFPP 40 mg } \\
n=101\end{array}$ & $\begin{array}{l}\text { SFPP 80 mg } \\
n=100\end{array}$ \\
\hline $\begin{array}{l}\text { Age (years), mean } \pm \text { SD } \\
\text { Gender, } n(\%)\end{array}$ & $66.3 \pm 11.8$ & $66.2 \pm 12.1$ & $66.4 \pm 11.5$ \\
Male & $50(24.9)$ & $29(28.7)$ & $21(21.0)$ \\
Female & $151(75.1)$ & $72(71.3)$ & $79(79.0)$ \\
Weight $(\mathrm{kg})$, mean $\pm \mathrm{SD}$ & $60.46 \pm 11.55$ & $59.11 \pm 10.54$ & $61.82 \pm 12.38$ \\
BMI $\left(\mathrm{kg} / \mathrm{m}^{2}\right)$, mean $\pm \mathrm{SD}$ & $24.76 \pm 3.86$ & $24.21 \pm 3.06$ & $25.32 \pm 4.48$ \\
\hline
\end{tabular}

$S D$ standard deviation, $B M I$ body mass index 
Fig. 1 Patient disposition. SFPP S-flurbiprofen plaster

Table 3 Application periods for the S-flurbiprofen plaster (SFPP)

Table 4 Drug-related adverse events at the application sites (skin symptoms)

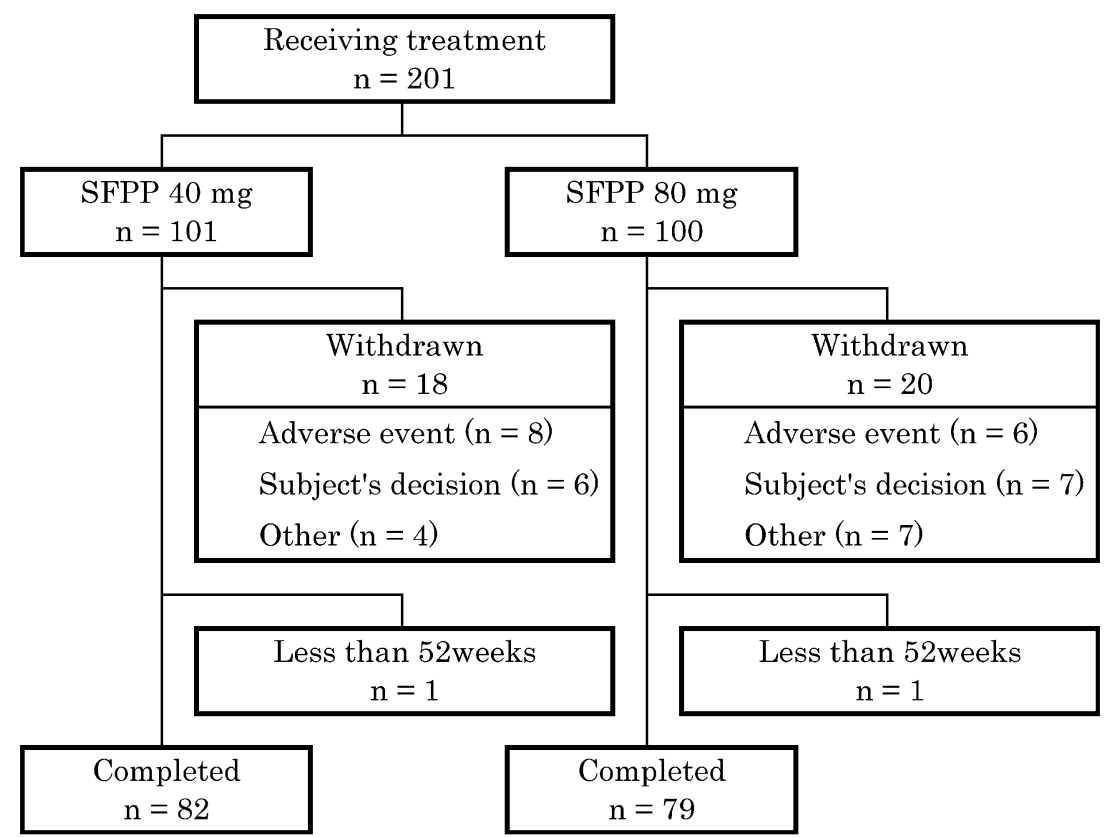

\begin{tabular}{lccc}
\hline $\begin{array}{l}\text { Application periods } \\
\text { (weeks), } n(\%)\end{array}$ & $\begin{array}{l}\text { All subjects } \\
n=201\end{array}$ & $\begin{array}{l}\text { SFPP 40 mg } \\
n=101\end{array}$ & $\begin{array}{l}\text { SFPP 80 mg } \\
n=100\end{array}$ \\
\hline $0-11$ & $7(3.5)$ & $4(4.0)$ & $3(3.0)$ \\
$12-23$ & $15(7.5)$ & $7(6.9)$ & $8(8.0)$ \\
$24-35$ & $11(5.5)$ & $5(5.0)$ & $6(6.0)$ \\
$36-51$ & $7(3.5)$ & $3(3.0)$ & $4(4.0)$ \\
$52-$ & $161(80.1)$ & $82(81.2)$ & $79(79.0)$ \\
\hline
\end{tabular}

\begin{tabular}{lcllcc}
\hline & $\begin{array}{l}\text { Total } \\
n=301\end{array}$ & $\begin{array}{l}\text { Knee } \\
n=192\end{array}$ & $\begin{array}{l}\text { Lumbar spine } \\
n=66\end{array}$ & $\begin{array}{l}\text { Cervical spine } \\
n=26\end{array}$ & $\begin{array}{l}\text { Other }^{\text {a }} \\
n=17\end{array}$ \\
\hline Drug-related AEs, $n(\%)$ & $141(46.8)$ & $94(49.0)$ & $30(45.5)$ & $11(42.3)$ & $6(35.3)$ \\
Application site dermatitis & $88(29.2)$ & $62(32.3)$ & $14(21.2)$ & $6(23.1)$ & $6(35.3)$ \\
Application site eczema & $32(10.6)$ & $21(10.9)$ & $8(12.1)$ & $3(11.5)$ & \\
Application site erythema & $17(5.6)$ & $10(5.2)$ & $4(6.1)$ & $3(11.5)$ & \\
Application site pruritus & $10(3.3)$ & $2(1.0)$ & $6(9.1)$ & $2(7.7)$ & \\
Application site discoloration & $3(1.0)$ & $3(1.6)$ & & & \\
\hline
\end{tabular}

$A E s$ adverse events

a Shoulder, elbow, hip, hallux, thoracic spine, and ankle

dermatitis, eczema, and erythema, and were mild and moderate in severity in 126 and 15 sites, respectively. None of the AEs at the sites were rated as severe. AEs at 128 sites were resolved by interruption of SFPP or by drug treatment, which allowed for study continuation until the end of the study period. The AEs at the remaining 13 sites necessitated discontinuation of the study; however, these AEs were resolved after the study discontinuation.
Systemic drug-related AEs occurred in 18 of the 201 patients (Table 5). Gastrointestinal disorders, such as gastritis and abdominal discomfort, were observed in nine patients and laboratory abnormalities, such as increased blood urea, were observed in seven patients. In addition, hepatic function disorder, colon adenomatous polyp, and generalized dermatitis were observed in one patient each. Among the nine patients in whom gastrointestinal disorders 
were observed, severe gastric ulcer hemorrhage was observed in one patient, whereas the symptoms were mild in the other patients. The patient with the gastric ulcer hemorrhage complication underwent endoscopic hemostasis because of the occurrence of nausea and hematemesis at 129 days after the SFPP application. The patient discontinued the study at 22 days after symptom onset, and received treatment with proton pump inhibitors. The symptoms were resolved 81 days thereafter. Although gastric ulcer hemorrhage was observed in the patient suffering from atrophic gastritis due to a Helicobacter pylori infection, a possible relation between SFPP and gastric ulcer hemorrhage could not be excluded.

\subsection{Laboratory Tests and Vital Signs}

The blood urea nitrogen (BUN) levels increased in the two treatment groups 2 weeks after the SFPP application compared with those at baseline; however, they stabilized thereafter. The maximum mean change from baseline was $1.91 \mathrm{mg} / \mathrm{dL}$ for the SFPP 40-mg group (baseline, $15.11 \mathrm{mg} / \mathrm{dL}$ ) and $1.89 \mathrm{mg} / \mathrm{dL}$ for the SFPP $80-\mathrm{mg}$ group (baseline, $16.12 \mathrm{mg} / \mathrm{dL}$ ). The creatinine levels increased 44 weeks after the SFPP application compared with those at baseline. The maximum mean change from baseline was $0.019 \mathrm{mg} / \mathrm{dL}$ for the SFPP 40-mg group (baseline, $0.678 \mathrm{mg} / \mathrm{dL}$ ) and $0.022 \mathrm{mg} / \mathrm{dL}$ for the SFPP 80-mg group (baseline, $0.678 \mathrm{mg} / \mathrm{dL}$ ) (Table 6).

Statistically significant changes were found in some of the laboratory parameters and vital signs assessed; however, these changes were not clinically significant.

\subsection{Efficacy Evaluations}

In the patient's global assessment (Fig. 2a), the score "marked" appeared at 2 weeks after the SFPP application,
Table 5 Systemic adverse events

\begin{tabular}{|c|c|c|c|}
\hline & $\begin{array}{l}\text { Total } \\
n=201\end{array}$ & $\begin{array}{l}\text { SFPP } 40 \mathrm{mg} \\
n=101\end{array}$ & $\begin{array}{l}\text { SFPP } 80 \mathrm{mg} \\
n=100\end{array}$ \\
\hline $\mathrm{AE}$ & $168(83.6)$ & $82(81.2)$ & $86(86.0)$ \\
\hline Drug-related AE & $18(9.0)$ & $6(5.9)$ & $12(12.0)$ \\
\hline SAE & $8(4.0)$ & $3(3.0)$ & $5(5.0)$ \\
\hline Drug-related $\mathrm{SAE}^{\mathrm{a}}$ & $1(0.5)$ & $1(1.0)$ & \\
\hline \multicolumn{4}{|l|}{ Drug-related AEs } \\
\hline \multicolumn{4}{|l|}{ Gastrointestinal disorders } \\
\hline Gastritis & $4(2.0)$ & $1(1.0)$ & $3(3.0)$ \\
\hline Abdominal discomfort & $2(1.0)$ & $1(1.0)$ & $1(1.0)$ \\
\hline Gastric ulcer hemorrhage $^{\mathrm{a}}$ & $1(0.5)$ & $1(1.0)$ & \\
\hline Gastric ulcer & $1(0.5)$ & & $1(1.0)$ \\
\hline Duodenal ulcer & $1(0.5)$ & & $1(1.0)$ \\
\hline Gastro-esophageal reflux disease & $1(0.5)$ & & $1(1.0)$ \\
\hline Abdominal pain upper & $1(0.5)$ & & $1(1.0)$ \\
\hline Dyspepsia & $1(0.5)$ & & $1(1.0)$ \\
\hline \multicolumn{4}{|l|}{ Investigations } \\
\hline Blood urea increased & $4(2.0)$ & $1(1.0)$ & $3(3.0)$ \\
\hline Blood creatinine increased & $1(0.5)$ & $1(1.0)$ & \\
\hline Blood urine present & $3(1.5)$ & $1(1.0)$ & $2(2.0)$ \\
\hline Protein urine present & $1(0.5)$ & & $1(1.0)$ \\
\hline Occult blood & $1(0.5)$ & & $1(1.0)$ \\
\hline \multicolumn{4}{|l|}{ Hepatobiliary disorders } \\
\hline Hepatic function abnormal & $1(0.5)$ & & $1(1.0)$ \\
\hline \multicolumn{4}{|c|}{ Neoplasms benign, malignant, and unspecified (including cysts and polyps) } \\
\hline Colon adenoma & $1(0.5)$ & & $1(1.0)$ \\
\hline \multicolumn{4}{|c|}{ Skin and subcutaneous tissue disorders } \\
\hline Dermatitis & $1(0.5)$ & $1(1.0)$ & \\
\hline
\end{tabular}

Values are given as $n(\%)$

$A E$ adverse event, $S A E$ serious adverse event

${ }^{a}$ Gastric ulcer hemorrhage was a drug-related SAE 
and the percentage of "marked" increased continuously until 52 weeks after the SFPP application, reaching $44.2 \%$ (72/163 patients; 45.8 and $42.5 \%$ for the SFPP 40-mg and 80-mg groups, respectively). The percentage of the improvement (the sum of "marked" and "moderate") was $72.4 \%(118 / 163$ patients; $73.5 \%$ and $71.3 \%$ for the SFPP 40- and 80-mg groups, respectively) at 52 weeks after the SFPP application.

Similarly, in the clinician's global assessment (Fig. 2b), the score "marked" appeared at 2 weeks after the SFPP application, and the percentage of "marked" increased continuously until 52 week after the SFPP application, reaching $46.0 \%$ (75/163 patients; $45.8 \%$ and $46.3 \%$ for the SFPP 40-mg and 80-mg groups, respectively). The percentage of the improvement was $74.8 \%(122 / 163$ patients; 74.7 and $75.0 \%$ for the SFPP 40- and 80-mg groups, respectively) 52 weeks after the SFPP application.

Figure $2 \mathrm{c}$ shows the time-course changes in the tCS per site to be assessed. The mean \pm standard error of the tCS for all sites was $6.2 \pm 0.1,4.5 \pm 0.1$, and $1.8 \pm 0.1$ at baseline, 2 weeks, and 52 weeks after the SFPP application, thus improving the tCS by $4.4 \pm 0.1$ points at
Table 6 Time-course changes in the laboratory tests

\begin{tabular}{|c|c|c|c|}
\hline Time of assessment & Number of patients & $\begin{array}{l}\text { BUN } \\
(\mathrm{mg} / \mathrm{dL})\end{array}$ & $\begin{array}{l}\text { Creatinine } \\
(\mathrm{mg} / \mathrm{dL})\end{array}$ \\
\hline \multicolumn{4}{|l|}{ SFPP $40 \mathrm{mg}$} \\
\hline Baseline & 101 & $15.11 \pm 0.36$ & $0.678 \pm 0.016$ \\
\hline 2 weeks & 100 & $16.17 \pm 0.40^{*}$ & $0.681 \pm 0.015$ \\
\hline 4 weeks & 100 & $16.56 \pm 0.43^{*}$ & $0.682 \pm 0.016$ \\
\hline 8 weeks & 100 & $16.19 \pm 0.43^{*}$ & $0.671 \pm 0.015$ \\
\hline 12 weeks & 97 & $16.46 \pm 0.39 *$ & $0.687 \pm 0.015$ \\
\hline 16 weeks & 94 & $15.92 \pm 0.40^{*}$ & $0.685 \pm 0.016$ \\
\hline 20 weeks & 92 & $15.86 \pm 0.36$ & $0.681 \pm 0.016$ \\
\hline 24 weeks & 89 & $16.46 \pm 0.48^{*}$ & $0.683 \pm 0.016$ \\
\hline 28 weeks & 90 & $16.73 \pm 0.43^{*}$ & $0.674 \pm 0.016$ \\
\hline 32 weeks & 85 & $16.41 \pm 0.42^{*}$ & $0.673 \pm 0.016$ \\
\hline 36 weeks & 84 & $16.21 \pm 0.39^{*}$ & $0.681 \pm 0.016$ \\
\hline 40 weeks & 84 & $16.45 \pm 0.42^{*}$ & $0.676 \pm 0.016$ \\
\hline 44 weeks & 84 & $16.60 \pm 0.40^{*}$ & $0.680 \pm 0.017$ \\
\hline 48 weeks & 84 & $16.58 \pm 0.46^{*}$ & $0.684 \pm 0.016$ \\
\hline 52 weeks & 81 & $16.97 \pm 0.51^{*}$ & $0.697 \pm 0.016^{*}$ \\
\hline \multicolumn{4}{|l|}{ SFPP $80 \mathrm{mg}$} \\
\hline Baseline & 100 & $16.12 \pm 0.37$ & $0.678 \pm 0.013$ \\
\hline 2 weeks & 97 & $17.39 \pm 0.43^{*}$ & $0.684 \pm 0.014$ \\
\hline 4 weeks & 98 & $17.70 \pm 0.44^{*}$ & $0.690 \pm 0.015$ \\
\hline 8 weeks & 99 & $17.28 \pm 0.35^{*}$ & $0.682 \pm 0.013$ \\
\hline 12 weeks & 96 & $17.13 \pm 0.34 *$ & $0.685 \pm 0.013$ \\
\hline 16 weeks & 95 & $17.16 \pm 0.40^{*}$ & $0.685 \pm 0.014$ \\
\hline 20 weeks & 90 & $17.15 \pm 0.45^{*}$ & $0.683 \pm 0.014$ \\
\hline 24 weeks & 88 & $16.44 \pm 0.42$ & $0.683 \pm 0.015$ \\
\hline 28 weeks & 83 & $17.18 \pm 0.39 *$ & $0.675 \pm 0.015$ \\
\hline 32 weeks & 83 & $17.23 \pm 0.46^{*}$ & $0.691 \pm 0.016$ \\
\hline 36 weeks & 83 & $17.61 \pm 0.51^{*}$ & $0.689 \pm 0.015$ \\
\hline 40 weeks & 82 & $17.58 \pm 0.45^{*}$ & $0.692 \pm 0.015$ \\
\hline 44 weeks & 81 & $17.66 \pm 0.47^{*}$ & $0.701 \pm 0.016^{*}$ \\
\hline 48 weeks & 81 & $17.86 \pm 0.51^{*}$ & $0.701 \pm 0.017 *$ \\
\hline 52 weeks & 79 & $16.70 \pm 0.45$ & $0.701 \pm 0.016^{*}$ \\
\hline
\end{tabular}

Values are given as mean \pm standard error

Normal ranges: BUN, 6-20 mg/dL; creatinine, 0.61-1.04 mg/dL (males) and 0.47-0.79 mg/dL (females) $B U N$ blood urea nitrogen

$* p<0.05$ 


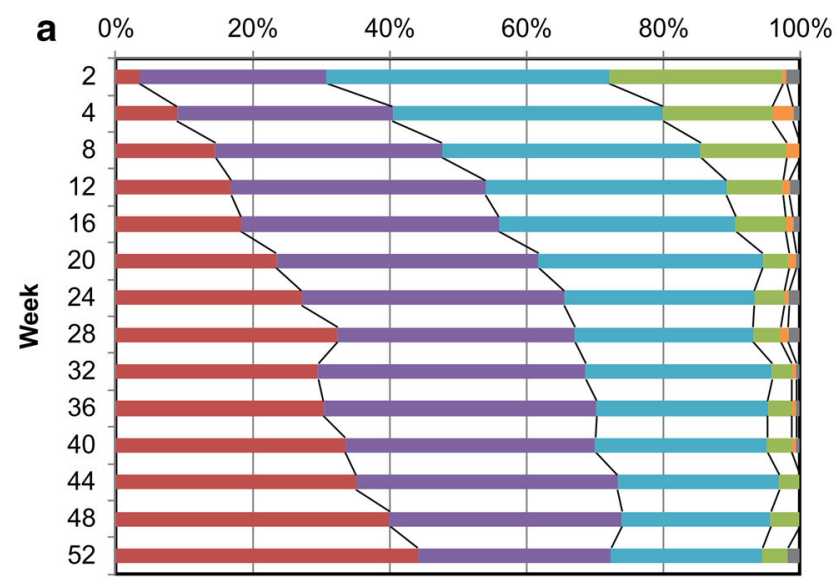

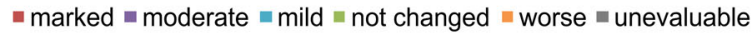

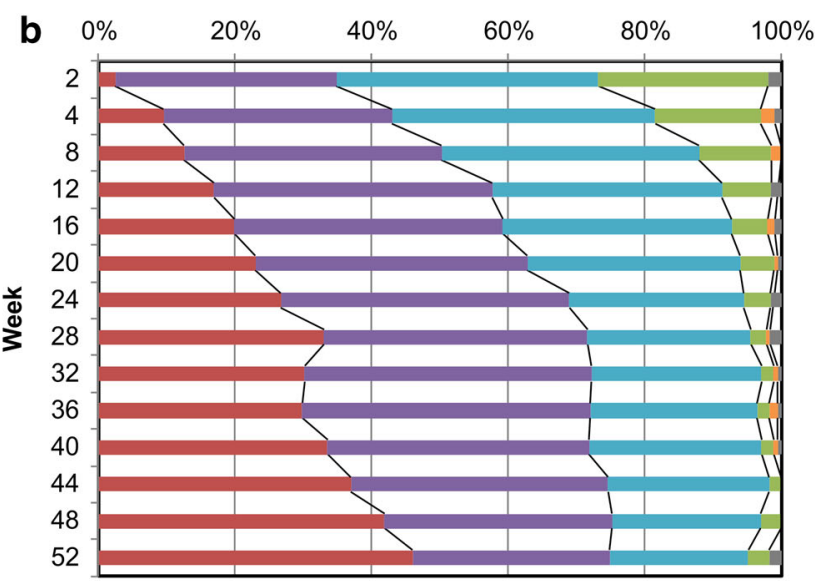

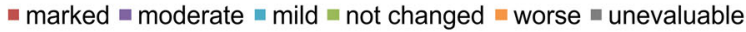

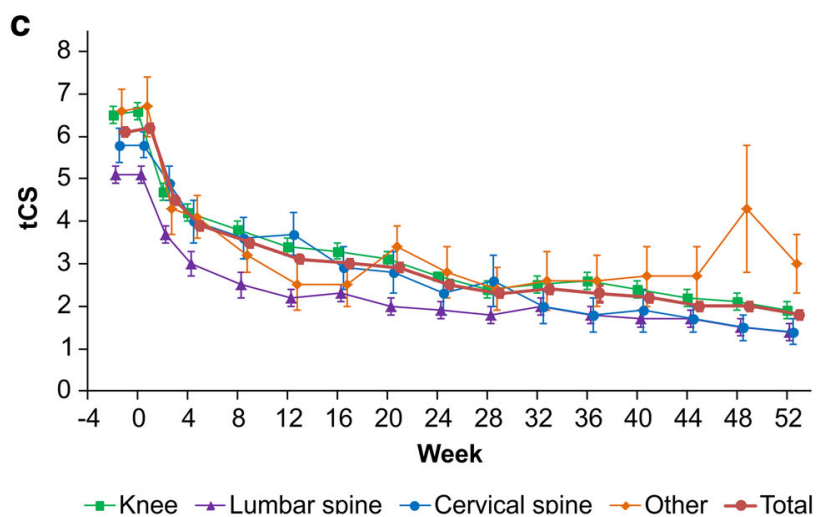

Fig. 2 a Patient's global assessment; b Clinician's global assessment; c time-course changes in the total clinical symptoms score ( $\mathrm{tCS}$, mean \pm standard error). $p$ values were calculated using a paired

52 weeks. The tCS improved significantly from 2 weeks after the SFPP application, and improved continuously until 52 weeks after the application for all sites assessed. In addition, the CS improved for all seven parameters compared to that at baseline (Table 7).

\section{Discussion}

In this study, the percentage of patients who continuously applied SFPP for 52 weeks (the completion rate) was high $(80.1 \%)$, which was much higher than the $50 \%$ completion rate of previous long-term (52 weeks) studies of topical NSAIDs in OA patients [17, 18]. Although these patients were expected to be in the consistent systemic exposure (consistently high blood concentration of SFP) with the higher adherence of SFPP throughout the study. Only $7.0 \%$ (14/201 patients) discontinued the study due to AEs. From these results, the present study suggested a relatively better safety profile for SFPP. $t$ test (two-sided, $5 \%$ significance level). Significant improvements from baseline were observed at all assessment time-points except at the 48-week time-point of "other." $t C S$ total clinical symptoms

In the safety assessment of SFPP, the most common drug-related AEs were skin symptoms at the application sites, and most of the drug-related systemic AEs were not considered clinically significant.

The incidence of drug-related AEs causing gastrointestinal symptoms, which are a class effect of NSAIDs, was $3.0 \%$ (3/101 patients) and $6.0 \%$ (6/100 patients) in the SFPP 40-mg and 80-mg groups, respectively. Of the nine patients with gastrointestinal symptoms, gastrointestinal ulcer was found in two patients; however, the other seven patients experienced only mild symptoms such as gastritis, and no study discontinuations due to drug-related AEs occurred. Therefore, the risk of gastrointestinal disorders caused by SFPP was considered lower than with oral administration $[19,20]$. The following two phenomena are reported in gastrointestinal disorders associated with oral NSAIDs: a decrease in endogenous prostaglandins (PGs) in the gastric mucosa induced by inhibition of plasma COX, and a direct effect of NSAIDs on the gastric mucosal epithelial cells [21-23]. SFP, which exhibits non-selective 


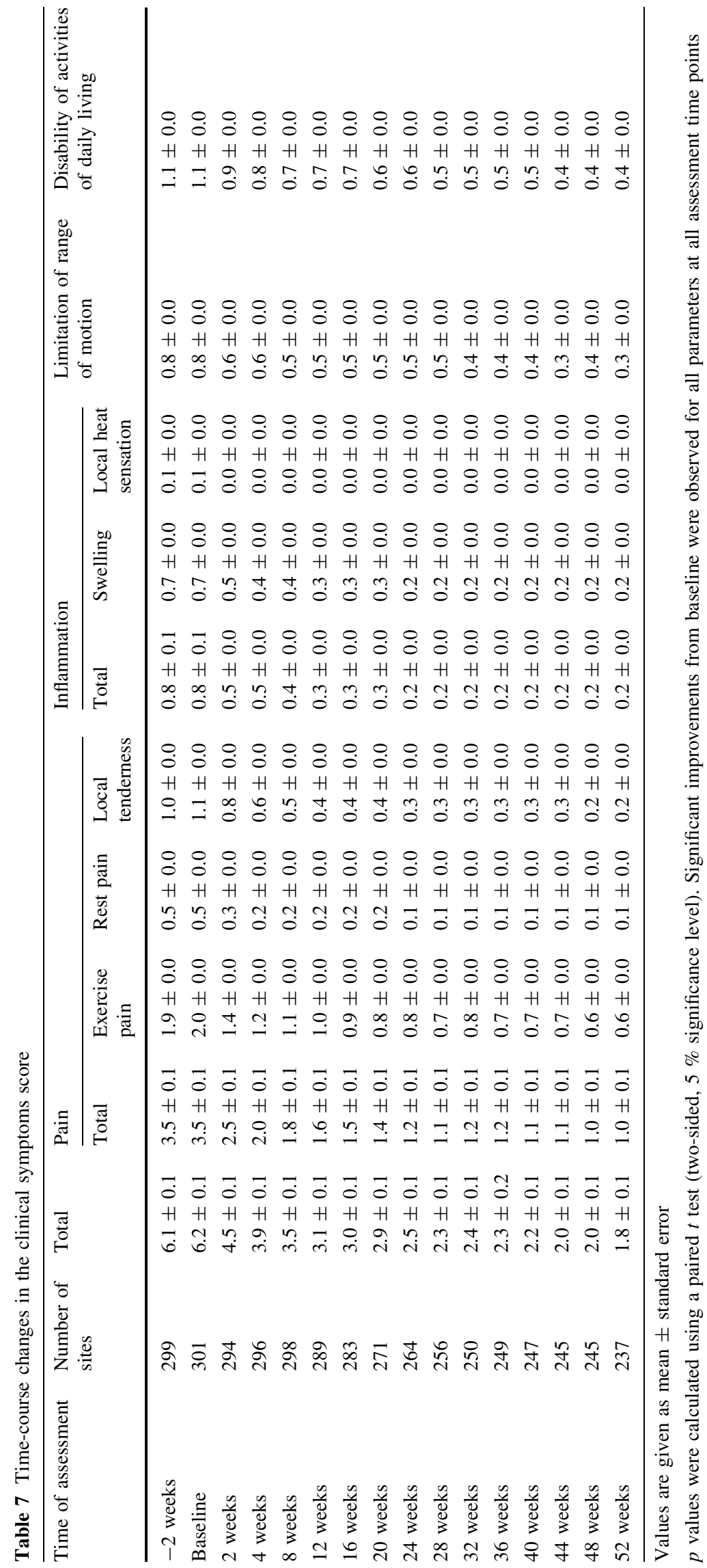


inhibition of COX-1 $\left(\mathrm{IC}_{50}=8.97 \mathrm{nM}\right)$ and COX-2 $\left(\mathrm{IC}_{50}=2.94 \mathrm{nM}\right)$ [24], induces gastrointestinal disorders by acting on the gastric mucosal cells. However, the transdermal administration of SFP did not induce gastric ulcer at exposures up to seven times the maximum plasma concentration $\left(C_{\max }\right)$ and ten times the area under the concentration-time curve (AUC) after oral administration to rats [14]; therefore, the effects on the digestive organs might be avoided by the transdermal administration of SFP. Similarly, there were no drug-related AEs causing renal disorders. A significant but small increase in BUN levels was observed in previous 2-week SFPP application studies $[14,15]$. Therefore, in the present study, we assessed the changes in the laboratory values of renal function-related parameters. Similar to these previous 2-week SFPP application studies, in the current study, a statistically significant increase in BUN levels was observed 2 weeks after the SFPP application, which did not increase further during the prolonged application periods. In addition, the creatinine levels significantly increased from 44 weeks after the SFPP application, although only slight changes in the mean values were observed and these values were within the normal range; therefore, we believe this finding does not suggest a clinically significant effect of SFPP on renal function.

Although patients with cardiovascular diseases, including a past history, were enrolled, no drug-related AEs classified as cardiovascular disorders are observed.

Statistically significant changes were found in some of the blood tests, urinalysis results, blood pressure, and pulse rate, although these changes were considered clinically insignificant.

In the present study, the major drug-related systemic AEs were also gastrointestinal disorders. Laboratory abnormalities were observed for a small number of patients, although these changes were observed for racemic flurbiprofen tablets $[19,20]$; therefore, no new drug-related AEs were observed in the present study.

Some topical NSAIDs are known to cause serious photosensitive dermatitis [25, 26], while FP is known to pose no such risk. The benzophenone moiety in chemical structures has been shown to contribute to photoallergic reactions [27, 28]. SFP does not contain a benzophenone moiety. In the current study, SFPP was applied to various sites for 52 weeks without restrictions such as protection from sunlight, and no photosensitivity dermatitis-related AEs were observed. Therefore, SFPP may be used safely without concern for photosensitivity dermatitis.

As application of SFPP was started without any washout period of former NSAIDs, we expected that the apparent improvement of SFPP seemed to be very difficult. Supprisingly, both the patient's and clinician's global assessments showed apparent improvements as early as 2 weeks after the SFPP application, and the improvement rates continued to increase over the following weeks until the end of the study. However, our study had major limitations such as a lack of a control group and randomization. The result of efficacy only showed the possibility and further studies including control groups would be necessary to confirm the immediate and long-lasting effects of SFPP.

Since the number of elderly persons in Japan will continue to increase in the near future, prevention of "locomotive syndrome," deterioration in locomotive function associated with locomotor disability, and extension of healthy life expectancy are challenges to be faced [29, 30]. $\mathrm{OA}$, the most common joint disease, is an important disease underlying locomotive syndrome. Arthralgia due to OA worsens locomotive function. Hopefully, SFPP could open new avenues for preventing the progression of functional disorders in OA patients.

\section{Conclusion}

SFPP did not cause safety concerns during its continuous application for up to 52 weeks in OA patients. Therefore, SFPP could be an additional pharmacotherapy in the treatment of OA.

Acknowledgments The authors would like to thank the clinicians who were involved in the clinical trial: Takashi Yokoyama, Sanshiro Hashimoto, Minako Murata, Fumitoshi Omura, Eijiro Okumura, Ko Matsumoto, and Koichi Tanaka (Tokyo); Minoru Irahara and Masashi Kimoto (Chiba); Ryoichi Yamazaki, Akira Kobayashi, and Ruriko Ozawa (Saitama). The authors would like to thank Yumiko Imadera of Taisho Pharmaceutical Co., Ltd. for assistance with drafting and revising this article.

\section{Compliance with Ethical Standards}

Conflict of interests Taisho Pharmaceutical Co., Ltd. was involved in the design of the study, its conduct, and the data analysis. I. Yataba, N. Otsuka, and I. Matsushita are employees of Taisho Pharmaceutical Co., Ltd. H. Matsumoto has received consultancy fees from Taisho Pharmaceutical Co., Ltd. Y. Hoshino had received consultancy fees from Taisho Pharmaceutical Co., Ltd. while in a previous affiliation.

Source of funding This study was sponsored by Taisho Pharmaceutical Co., Ltd.

Ethical approval All procedures performed in this study involving human participants were in accordance with the ethical standards of the institutional research committee at each participating study site and with the 1964 Helsinki Declaration and Good Clinical Practice guidelines.

Informed consent Informed consent was obtained from all individual participants included in the study.

Author contributions All authors were involved in drafting the article or revising it critically for important intellectual content, and all authors approved the final version for publication. I. Yataba and N. 
Otsuka had full access to all of the study data and take responsibility for the integrity of the data and the accuracy of the data analysis. Study conception and design: I. Yataba, N. Otsuka, I. Matsushita, H. Matsumoto, and Y. Hoshino. Data acquisition: I. Yataba. Data analysis and interpretation: I. Yataba, N. Otsuka, I. Matsushita, H. Matsumoto, and Y. Hoshino.

Open Access This article is distributed under the terms of the Creative Commons Attribution-NonCommercial 4.0 International License (http://creativecommons.org/licenses/by-nc/4.0/), which permits any noncommercial use, distribution, and reproduction in any medium, provided you give appropriate credit to the original author(s) and the source, provide a link to the Creative Commons license, and indicate if changes were made.

\section{References}

1. Muraki S, Akune T, Oka H, En-yo Y, Yoshida M, Saika A, et al. Association of radiographic and symptomatic knee osteoarthritis with health-related quality of life in a population-based cohort study in Japan: the ROAD study. Osteoarthritis Cartilage. 2010;18:1227-34. doi:10.1016/j.joca.2010.06.001.

2. Peat G, McCarney R, Croft P. Knee pain and osteoarthritis in older adults: a review of community burden and current use of primary health care. Ann Rheum Dis. 2001;60:91-7. doi:10.1136/ ard.60.2.91.

3. Bannuru RR, Schmid CH, Kent DM, Vaysbrot EE, Wong JB, McAlindon TE. Comparative effectiveness of pharmacologic interventions for knee osteoarthritis: a systematic review and network meta-analysis. Ann Intern Med. 2015;162:46-54. doi:10. 7326/M14-1231.

4. Wolfe MM, Lichtenstein DR, Singh G. Gastrointestinal toxicity of nonsteroidal antiinflammatory drugs. $\mathrm{N}$ Engl $\mathrm{J}$ Med. 1999;340:1888-99.

5. Zullo A, Hassan C, Campo SM, Morini S. Bleeding peptic ulcer in the elderly: risk factors and prevention strategies. Drugs Aging. 2007;24:815-28.

6. Barkin RL, Beckerman M, Blum SL, Clark FM, Koh EK, Wu DS. Should nonsteroidal anti-inflammatory drugs (NSAIDs) be prescribed to the older adult? Drugs Aging. 2010;27:775-89. doi:10. 2165/11539430-000000000-00000.

7. McAlindon TE, Bannuru RR, Sullivan MC, Arden NK, Berenbaum F, Bierma-Zeinstra SM, et al. OARSI guidelines for the non-surgical management of knee osteoarthritis. Osteoarthritis Cartilage. 2014;22:363-88. doi:10.1016/j.joca.2014.01.003.

8. Hochberg MC, Altman RD, April KT, Benkhalti M, Guyatt G, McGowan J, et al. American College of Rheumatology 2012 recommendations for the use of nonpharmacologic and pharmacologic therapies in osteoarthritis of the hand, hip, and knee. Arthritis Care Res (Hoboken). 2012;64:465-74. doi:10.1002/acr. 21596.

9. Brown GA. AAOS clinical practice guideline: treatment of osteoarthritis of the knee: evidence-based guideline, 2nd edition. J Am Acad Orthop Surg. 2013;21:577-9. doi:10.5435/JAAOS21-09-577.

10. Jordan KM, Arden NK, Doherty M, Bannwarth B, Bijlsma JW, Dieppe P, et al. EULAR Recommendations 2003: an evidence based approach to the management of knee osteoarthritis: Report of a Task Force of the Standing Committee for International Clinical Studies Including Therapeutic Trials (ESCISIT). Ann Rheum Dis. 2003;62:1145-55. doi:10.1136/ard.2003.011742.

11. National Institute for Health and Care Excellence. Osteoarthritis: Care and management in adults, https://www.nice.org.uk/ guidance/CG177;2014. Last accessed 25 April 2016.
12. Stanos S. Osteoarthritis guidelines: a progressive role for topical NSAIDs. J Am Osteopath Assoc. 2013;113:123-7.

13. Yataba I, Otsuka N, Matsushita I, Kamezawa M, Yamada I, Sasaki S, et al. Plasma pharmacokinetics and synovial concentrations of S-flurbiprofen plaster in humans. Eur J Clin Pharmacol. 2016;72:53-9. doi:10.1007/s00228-015-1960-6.

14. Medicine Interview Form of LOQOA ${ }^{\circledR}$ tape 40. Revised in January 2016 (Version 3). Opened in the Website of Pharmaceuticals and Medical Devices Agency, Japan. Available at http://www. pmda.go.jp/. Last accessed 25 April 2016.

15. Yataba I, Otsuka N, Matsushita I, Matsumoto H, Hoshino Y. Efficacy of S-flurbiprofen plaster in knee osteoarthritis treatment: results from a phase III, randomized, active-controlled, adequate and well-controlled trial. Mod Rheumatol. 2016;. doi:10.1080/ 14397595.2016.1176624.

16. Brune K, Patrignani P. New insights into the use of currently available non-steroidal anti-inflammatory drugs. J Pain Res. 2015;8:105-18. doi:10.2147/JPR.S75160.

17. Peniston JH, Gold MS, Alwine LK. An open-label, long-term safety and tolerability trial of diclofenac sodium $1 \%$ gel in patients with knee osteoarthritis. Phys Sportsmed. 2011;39:31-8. doi:10.3810/psm.2011.09.1918.

18. Shainhouse JZ, Grierson LM, Naseer Z. A long-term, open-label study to confirm the safety of topical diclofenac solution containing dimethyl sulfoxide in the treatment of the osteoarthritic knee. Am J Ther. 2010;17:566-76. doi:10.1097/MJT. 0b013e3181d169b5.

19. Ansaid $^{\circledR}$ (flurbiprofen) [package insert]. New York, NY, US: Pharmacia Upjohn company, Division of Pfizer, Inc.; 2010.

20. Froben $100 \mathrm{mg}$ Tablets (flurbiprofen) [package insert]. Maidenhead, Berkshire, UK: BGP Products, Ltd.; 2015.

21. Tomisato W, Tsutsumi S, Hoshino T, Hwang HJ, Mio M, Tsuchiya T, et al. Role of direct cytotoxic effects of NSAIDs in the induction of gastric lesions. Biochem Pharmacol. 2004;67:575-85.

22. Tomisato W, Tanaka K, Katsu T, Kakuta H, Sasaki K, Tsutsumi $\mathrm{S}$, et al. Membrane permeabilization by non-steroidal anti-inflammatory drugs. Biochem Biophys Res Commun. 2004;323:1032-9.

23. Sinha M, Gautam L, Shukla PK, Kaur P, Sharma S, Singh TP. Current perspectives in NSAID-induced gastropathy. Mediators Inflamm. 2013;2013:258209. doi:10.1155/2013/258209.

24. Sugimoto M, Toda Y, Hori M, Mitani A, Ichihara T, Sekine S, et al. Analgesic effect of the newly developed $\mathrm{S}(+)$-flurbiprofen plaster on inflammatory pain in a rat adjuvant-induced arthritis model. Drug Dev Res. 2016;77:20-8. doi:10.1002/ddr.21288.

25. European Medicines Agency. Assessment report for ketoprofen containing medicinal products (topical formulations). 2010. http://www.ema.europa.eu/ema. Last accessed 25 April 2016.

26. Guy RH, Kuma H, Nakanishi M. Serious photocontact dermatitis induced by topical ketoprofen depends on the formulation. Eur J Dermatol. 2014;24:365-71. doi:10.1684/ejd.2014.2332.

27. Nakazawa T, Shimo T, Chikamatsu N, Igarashi T, Nagata $O$, Yamamoto M. Study on the mechanism of photosensitive dermatitis caused by ketoprofen in the guinea pig. Arch Toxicol. 2006;80:442-8. doi:10.1007/s00204-006-0063-7.

28. Seto Y, Ohtake H, Kato M, Onoue S. Phototoxic risk assessments on benzophenone derivatives: photobiochemical assessments and dermal cassette-dosing pharmacokinetic study. J Pharmacol Exp Ther. 2015;354:195-202. doi:10.1124/jpet.115.223644.

29. Nakamura K. A "super-aged" society and the "locomotive syndrome". J Orthop Sci. 2008;13:1-2. doi:10.1007/s00776-007$1202-6$.

30. Nakamura K. The concept and treatment of locomotive syndrome: its acceptance and spread in Japan. J Orthop Sci. 2011;16:489-91. doi:10.1007/s00776-011-0108-5. 